\title{
Cinema de Observação: o Olhar Autoral
} Rodrigo Lacerda ${ }^{1}$

Anna Grimshaw e Amanda Ravetz. 2009. Observational Cinema. Anthropology, Film, and the Exploration of Social Life. Bloomington: Indiana University Press. 198pp. ISBN 978-025-3354-24-2.

Observational Cinema revisita o trabalho de alguns documentaristas conceituados, no sentido de resgatar a relevância daquela sensibilidade cinematográfica na compreensão e relação com o mundo e enquanto ferramenta metodológica e epistemológica da antropologia. Anna Grimshaw já tinha realizado um empreendimento semelhante em The Ethnographer's Eye: Ways of Seeing in Anthropology (2001), mas agora, em colaboração com Amanda Ravetz, cruza uma reapreciação dos textos fundamentais de André Bazin com desenvolvimentos recentes nas ciências sociais, nomeadamente nas aproximações fenomenológicas às questões do corpo, emoções, experiência, etc.

O primeiro capítulo examina os pontos de contacto e contaminações entre os ensaios de Bazin (especialmente, "A Ontologia da Imagem Fotográfica" e "O Mito do Cinema Total") e de Roger Sandall ("Observation and Identity" [1972]) e Colin Young ("Observational Cinema" [1974]), concluindo com o argumento que o cinema de observação é o herdeiro do neorrealismo de Roberto Rossellini e Vittorio de Sica. Para as autoras, esta abordagem cinematográfica, mais do que um género ou um conjunto de técnicas, é, acima de tudo, uma sensibilidade que se revela na relação ética do encontro e revelação do real. Nesse sentido, "Filmmakers were now less directors and more filters, drawing their audience into an active exploration of the world created through cinema." (Grimshaw e Ravetz, 2009: 21) Contudo, em aparente contradição, o cinema de observação é profundamente autoral porque se baseia na relação pessoal e única que o realizador estabelece com o sujeito do filme e com o próprio corpo deste. Apesar desta argumentação, as autoras reconhecem que existem determinadas técnicas, também antes identificadas por Bazin, que potenciam aquele olhar: planossequência longos com profundidade de campo e a preservação da unidade espacial e temporal dos eventos durante a filmagem e montagem.

\footnotetext{
${ }^{1}$ Universidade Nova de Lisboa, Faculdade de Ciências Sociais e Humanas, Centro em Rede de Investigação em Antropologia, 1069-061 Lisboa, Portugal.
} 
Os três capítulos seguintes examinam alguns filmes e realizadores fundamentais do cinema de observação. Sem pretenderem produzir uma enumeração exaustiva e histórica, Grimshaw e Ravetz concentram-se na exploração de diferentes abordagens, metodologias e olhares, começando com os pioneiros que apelidam de "social observers": Robert Drew (Primary [1960]), Albert e David Maysles (Salesman [1968]) e Frederick Wiseman (Titicut Follies [1967]). Segundo as autoras, para Drew, o papel do observador era testemunhar e acompanhar os eventos entre e ao nível das pessoas, submetendose, assim, aos encontrões destas, mas também ao imprevisível e inefável. Não obstante a horizontalidade do seu olhar, a formação jornalística de Drew levava-o a forçar a construção de narrativas clássicas constituídas por um acumular de tensão que devia conduzir a um clímax. Ecoando o cinema neorrealista e os ensaios de Bazin e Young, Grimshaw e Ravetz defendem que, no cinema de observação, a densidade dos detalhes e texturas da vida deve substituir a preocupação com a construção artificial de uma excitação ou emoção exterior à diegese.

De seguida, o livro detém-se em Salesman, dos irmãos Maysles, pelo qual as autoras evidenciam uma clara simpatia, uma vez que os realizadores construíram o filme a partir de uma relação próxima e humana com os seus sujeitos. Além disso, apesar de o documentário aludir a determinados estados interiores das pessoas que acompanha, evita explicá-los, convidando a audiência a elaborar a sua própria aproximação e compreensão. Já em relação a Titicut Follies, de Frederick Wiseman, Grimshaw e Ravetz são bastante críticas. As autoras consideram que o filme recorre a enquadramentos demasiado próximos que quebram a relação ética e as associações espaciais do cinema. Esta desorientação é exacerbada por uma montagem tipo mosaico que, apesar de manter a coesão narrativa interna a cada sequência, entra e sai destas abruptamente. Nesse sentido, Wiseman possui um estilo de observação "privilegiado", uma vez que não revela as características do olhar humano e não se coloca ao mesmo nível que as pessoas presentes no filme. A despeito da pertinência das críticas das autoras em relação àquele documentário (que é, de certo modo, utilizado no livro como exemplo de uma utilização incorreta do cinema de observação), teria sido mais exato não generalizar a apreciação particular à obra do realizador que, depois dos primeiros filmes, evidenciou uma evolução estilística, em parte, no sentido defendido por Grimshaw e Ravetz.

A segunda secção do livro é dedicada aos realizadores Herb Di Gioia, David Hancock e David MacDougall, alunos, nos anos sessenta, do curso "Ethnographic Film Program", desenvolvido por Colin Young na UCLA com o intuito de explorar os cruzamentos profícuos entre antropologia e cinema. Grimshaw e Ravetz definem a obra de Di Gioia e Hancock como um processo de investigação de olhares e metodologias no cinema de observação. Deste empreendimento, as 
autoras sublinham o recurso ao zoom como forma de exploração espacial que mantém a unidade temporal e a progressiva consciencialização de que o tipo de cinema em que estavam interessados se centrava no que acontecia durante a rodagem, devendo a montagem derivar daquela vivência e atitude. Da curta obra dos realizadores, o livro destaca Peter Murray (1981) - um filme de cinquenta minutos sobre um homem a fazer uma cadeira na sua oficina.

Using long takes, Hancock traces the distinctive way that the chair maker handles his materials and the rhythm of his practice. These extended, unbroken shots are not, however, fixed or static. They are dynamic - the energy being generated from within the shot itself by the camera's movement between different points of focus at it probes the relationship between part and whole, action and contemplation, figure and ground. (...) Hancock uses the camera not to transcend the limitations of the human eye but to create equivalents for its operations. (Grimshaw e Ravetz, 2009: 67)

O quarto capítulo, dedicado à obra de David MacDougall, estrutura-se segundo duas vertentes principais: por um lado, analisando o trabalho de um dos mais importantes realizadores contemporâneos de filmes etnográficos que recorre ao cinema de observação; por outro, para iniciar uma exploração das relações e tensões entre esta sensibilidade cinematográfica e a produção de conhecimento nas ciências sociais. Após uma breve análise do seu primeiro filme, To Live with Herds (1972), realizado em parceria com Judith MacDougall, sua esposa, e galardoado no Festival de Veneza, Grimshaw e Ravetz debruçam-se com maior profundidade no estudo antropológico que MacDougall encetou no Doon School, um colégio interno situado na Índia. Este longo trabalho de campo deu origem a cinco documentários que são analisados no livro: Doon School Chronicles (2000), With Morning Hearts (2001), Karam in Jaipur (2001), The New Boys (2003), e The Age of Reason (2004). Nestes filmes, particularmente no primeiro, MacDougall explora as potencialidades da "coapresentação" de vários elementos de um modo não linear (por oposição à escrita que discorre de um modo sequencial e linear), evidenciando assim as relações entre as subjetividades individuais e os elementos materiais, sociais, estéticos, filosóficos e simbólicos da escola. Além disso, o realizador assume maioritariamente um papel de "filtro da realidade", deixando-se levar pela agencialidade das crianças - enquanto estas exploram e aprendem sobre o seu mundo, o cineasta, o filme e a audiência acompanham o movimento físico e conceptual daquelas, aprendendo com e sobre elas. Apesar desta abordagem, MacDougall interage, por vezes, com os rapazes, fazendo-lhes perguntas, podendo-se falar de uma câmara, recorrendo à terminologia do realizador, alternadamente "responsive" (que não interage com o sujeito), "interactive" (que procura e regista as interações com o sujeito) e "constructive" (que fragmenta e remonta o sujeito segundo uma lógica externa a este). 
Por fim, a última secção do livro reflete mais especificamente sobre as contribuições metodológicas do cinema de observação para a antropologia, mas também sobre como é que esta sensibilidade cinematográfica pode questionar e reformular a produção de conhecimento nas ciências sociais. Tal como menciona MacDougall (citado em Grimshaw e Ravetz, 2009: 131), “(...) instead of simply adding to anthropology's fields of study [visual anthropology] poses fundamental challenges to anthropological ways of 'speaking' and knowing." Segundo as autoras, as respostas a estas questões encontram-se na arena da antropologia associada à fenomenologia, com autores como Michael Jackson, Tim Ingold e Michael Taussig.

Jackson, por exemplo, tem argumentado que a antropologia se deve centrar no estudo da esfera humana quotidiana de sociabilidade, ação e consciência, que ele denomina como "lifeworld". De um modo semelhante, Ingold recusa a divisão do ser humano em partes autónomas, como corpo, mente e cultura, e advoga que aquele deve ser entendido enquanto entidade única e complexa imersa numa densa rede de relações com outros seres vivos e o mundo material. Além disso, para este antropólogo, o conhecimento é frequentemente transmitido por "enskillment", um modo de aprendizagem que envolve a participação ativa e continuada do sujeito no mundo. Assim, se até agora, na antropologia, os realizadores de cinema de observação têm sido subjugados e avaliados segundo critérios de uma ciência logocêntrica, a "viragem fenomenológica" oferece um enquadramento teórico promissor para a exploração das peculiaridades e potencialidades da imagem cinematográfica.

Enquanto o trabalho de Jackson e Ingold permite compreender o olhar e o conhecimento que o cinema de observação poderá desvendar, a obra de Taussig sobre mimesis e alteridade, desenvolvida a partir das teorizações de Walter Benjamin, explica como aquele saber pode ser transmitido. De facto, se o estudo do mundo não é transformado em abstrações (estruturas, categorias, sistemas) no cinema, como é que aquele pode ser útil e comunicado? Para Taussig, mimesis é um tipo de conhecimento que permite tomar posse de algo por meio da sua similitude. Este processo ocorre através de "copy" e "contact", que estabelece uma relação sensitiva entre o objeto e o sujeito. Deste modo, o autor advoga que, ao contrário do modelo distanciado do Iluminismo, a visão é um modo de conhecimento sensível. Tendo em conta este enquadramento, Grimshaw e Ravetz argumentam que,

Observational cinema, contrary to much critical opinion, is not then about creating an accurate transcription of the world. Instead it hinges upon connection, expressed in an almost intangible, empathic moment. (...) Hence, once we take seriously the possibility of knowledge through contact, we are able to recognize the imperative of an imaginative leap at the heart of observational cinema. (Grimshaw e Ravetz, 2009: 136) 
Não obstante algumas declarações mais vincadas, é importante sublinhar que a análise das relações entre antropologia, fenomenologia e cinema é relativamente curta e genérica. Para algumas abordagens mais complexas, mesmo que não desprovidas de deficiências e contradições, recomenda-se, por exemplo, The Corporeal Image: Film, Ethnography, and the Senses (2006), de David MacDougall, e The Skin of Film: Intercultural Cinema (2000), de Laura Marks. Além disso, os três filmes escolhidos por Grimshaw e Ravetz para refletir sobre as potencialidades desta abordagem são, apesar de interessantes, ainda breves e hesitantes experiências, porventura mais homogéneos na utilização de técnicas (por exemplo, planossequência longos) do que na coerência do olhar - ironicamente, uma distinção fulcral para as autoras nos primeiros capítulos do livro. É também de realçar que, a despeito de uma ressalva numa curta frase, a ênfase colocada na abordagem fenomenológica na secção final parece ofuscar as contribuições do cinema de observação para outras questões da antropologia ou, de um modo mais geral, para a compreensão do mundo que nos rodeia. O primeiro filme de MacDougall, To Live With Herds, por exemplo, é um contributo fundamental para o estudo da situação dos pastores Jie após a independência do Uganda.

O cinema de observação é frequentemente descrito, de um modo equivocado e ingénuo, como um realizador a andar com uma câmara atrás de pessoas à espera que algo aconteça e tem vindo a ser preterido a favor de outras abordagens mais "elaboradas", como o filme-ensaio. Observational Cinema leva-nos à essência desta sensibilidade cinematográfica e relembra-nos a importância do olhar na construção, transmissão e corporalização do conhecimento. Nesse sentido, é um singelo e complexo regresso ao que é essencial ao ser humano e um importante contributo para todos os interessados no cinema, dentro ou fora da antropologia. 